\title{
Updates on the epidemiology and risk factors for penile cancer
}

\author{
Antoin Douglawi, Timothy A. Masterson \\ Department of Urology, Indiana University School of Medicine, Indianapolis, IN, USA \\ Contributions: (I) Conception and design: All authors; (II) Administrative support: None; (III) Provision of study materials or patients: None; (IV) \\ Collection and assembly of data: All authors; (V) Data analysis and interpretation: All authors; (VI) Manuscript writing: All authors; (VII) Final \\ approval of manuscript: All authors. \\ Correspondence to: Timothy A. Masterson. Department of Urology, Indiana University School of Medicine, Indianapolis, IN, USA. Email: tamaster@iupui.edu.
}

\begin{abstract}
Penile cancer is a rare neoplasm representing less than $1 \%$ of all malignancies in the USA and Europe but is a significant public health hazard in the developing world. Male neonatal circumcision has been associated with a dramatic decrease in penile cancer rates with countries such as Israel, where circumcision is widely performed, having the lowest incidence in the world at $<0.1 \%$ of malignancies. Many risk factors have been identified for penile cancer including phimosis, lack of circumcision, obesity, lichen sclerosis, chronic inflammation, smoking, UVA phototherapy, socioeconomic status, human papillomavirus (HPV) infection and immune compromised states. The relationship between these factors and invasive disease varies and continues to be investigated. Our objective was to present a contemporary overview of the epidemiology and risk factors for invasive penile cancer.
\end{abstract}

Keywords: Penile cancer; epidemiology; risk factors; etiology; circumcision

Submitted Jan 09, 2017. Accepted for publication May 03, 2017.

doi: $10.21037 /$ tau.2017.05.19

View this article at: http://dx.doi.org/10.21037/tau.2017.05.19

\section{Introduction}

Penile cancer is a rare neoplasm most common in men aged $50-70$ years old $(1,2)$. While it is highly treatable in its early stages, treatment usually confers significant physical and psychological consequences. Fear and embarrassment in addition to social stigma result in the delay of seeking treatment by up to 1 year in $15-50 \%$ of patients (3). The most common site for penile cancer is the glans, which accounts for $48 \%$ of diagnoses, followed by prepuce $(21 \%)$, glans and prepuce $(9 \%)$, coronal sulcus $(6 \%)$ and uncommonly the shaft $(<2 \%)(2)$. The most common histologic subtype is squamous cell carcinoma, which accounts for $95 \%$ of diagnosed lesions. Other nonsquamous subtypes include sarcoma, melanoma, basal cell carcinoma and lymphoma (2). In this manuscript, we provide a contemporary update on the epidemiology and various risk factors associated with development of penile cancer.

\section{Epidemiology}

Penile cancer accounts for $0.4-0.6 \%$ of malignant diagnoses in the USA and Europe, and is responsible for $0.1 \%$ of cancer deaths $(4,5)$. In contrast, the incidence is significantly higher in developing countries where penile cancer constitutes a significant public health hazard. Countries that suffer from economic disparity or have low rates of circumcision such as Brazil, India and African nations, have the highest reported incidence with rates as high as $6 \%$ of malignant neoplasms (3). Conversely, countries with robust medical systems and religious practices leading to high rates of circumcision, such as Israel, report the lowest incidence at 0.1 in $100,000(1,6)$.

Brazil has the highest incidence with 2.8-6.8 per 100,000 , and penile cancer is the fourth most common tumor in men $(7,8)$. Within the country, a geographical and socioeconomic distribution is evident. Penile cancer accounts for $2.1 \%$ of male malignancies country wide. However, the Northeast region reports 5.7\%, much higher compared to the more economically developed Southeast region which reports penile cancer to account for only $1.2 \%$ of malignancy in males (7). Those affected were more likely to be white, smokers, uncircumcised, in their $6^{\text {th }}$ decade of 
Table 1 Summary of factors affecting the incidence of penile squamous cell carcinoma

\begin{tabular}{l}
\hline Risk factors \\
Lack of circumcision \\
Phimosis \\
Poor genital hygiene \\
Low socioeconomic status \\
Never married/divorced \\
UVA phototherapy \\
HPV \\
HIV/immune compromise \\
Lichen sclerosis \\
Obesity \\
Smoking \\
Erythroplasia or Queyrat/Bowen's disease \\
Protective factors \\
Circumcision (neonatal) \\
Public health advancements (improved hygiene) \\
HPV vaccination \\
Genital shielding in UVA therapy \\
\hline WA, ultraviot A; HPV, human papilomavir.
\end{tabular}

UVA, ultraviolet A; HPV, human papillomavirus.

life, and have a low socioeconomic status (9).

In developed nations, penile cancer is a fairly rare diagnosis. Incidence in the USA was historically reported to be decreasing from 0.84 per 100,000 in the late 1970 s to 0.58 in the $1990 \mathrm{~s}$ (10). A subsequent study examining SEER database data for nearly 5,000 men from 1998 to 2003 reported an incidence 0.81 per 100,000 (11). Asians and pacific Islanders had the lowest rates while Hispanics had much higher rates with a reported $72 \%$ increased risk compared to non-Hispanics. A higher incidence was also noted in southern states with lower socioeconomic status (11). The incidence in Europe and the United Kingdom are similar to USA with rates ranging between $0.45-1.7$ per 100,000 (12), however, while incidence in Europe and the USA has been on a decline, a recent article reported an increase in incidence in the UK from 1.1 to 1.33 in 100,000 men between 1979 and 2009. This rise coincided with the post WWII sexual revolution and greater exposure to HPV and other sexually transmitted diseases (13).

\section{Risk factors}

While invasive penile malignancies are known to most commonly afflict men in their $6^{\text {th }}$ decade of life, any male can be affected. Numerous risk factors have been shown to increase the risk of developing invasive disease. Phimosis, lack of circumcision, obesity, smoking, UVA phototherapy, and socioeconomic status have all been studied for many years (Table 1). There has also been increased interest in $\mathrm{HPV}$ infection and immune compromised states as possible inciting factors for the development of a penile malignancy. Each factor is outlined below in detail.

\section{Lack of circumcision}

The lack of circumcision is a well-accepted risk factor for penile cancer. In fact, it provides a virtually absolute protection against the disease when performed in the neonatal period (14). The diagnosis of penile cancer in an adult circumcised as a neonate is so rare, it often warrants a case report (4). The protective effect of circumcision was first reported in 1932 in a large cohort study of penile cancer patients that revealed a stark demographic anomaly, as there were zero cases in the Jewish patients $(15,16)$. A later report spanning the 1940 s to 1990 s, showed that out of 50,000 cases of penile cancer only 10 were in males with neonatal circumcisions; a ratio of uncircumcised to circumcised men of 5,000:1 (17). The protective mechanisms of circumcision are thought to be owed to improved hygiene, decreased risk of HPV and HIV transmission, as well as reduced chronic inflammation and balanitis (12). A recent systematic review by Larke et al. found a strong protective effect of early circumcision on invasive penile cancer with an odds ratio (OR) of 0.33 . Conversely, circumcision in adulthood appeared to increase the risk of invasive disease (OR 2.71), but the result may be due to selection bias (15).

\section{Phimosis and poor hygiene}

Phimosis is a pathologic inability to retract the foreskin and can be found in $25-75 \%$ of penile cancer patients $(3,18)$. It is a potent risk factor for penile cancer with OR range of 4.9-37.2 and likely facilitates the increased risk seen with lack of circumcision (15). The condition can lead to poor hygiene and accumulation of smegma under the preputial skin, which was historically thought to be involved in the carcinogenesis of penile cancer (19). However, that connection was contested in a 2006 manuscript which found no scientific evidence that smegma has any harmful effects (20). On the other hand, both balanitis and posthitis (inflammation of the preputial skin) can be exacerbated by 
phimosis, and have been linked to development of invasive penile malignancies (21).

A number of studies have attributed an increase in penile cancer to poor penile hygiene. That effect was highlighted in a Danish population-based study of cases diagnosed between 1943-1990 which reported a progressive decrease in incidence over time (22). Denmark has a largely uncircumcised population with $<2 \%$ of males undergoing the procedure before age 15 which implies that the observed decreased incidence could not be attributed to increased circumcision rates $(22,23)$. Rather, it was postulated that better hygiene contributed to the effect as the proportion of Danish dwellings with a bath increased incrementally from $35 \%$ in 1940 to $90 \%$ in 1990 (22).

\section{Lichen sclerosis and inflammatory conditions}

Chronic inflammation is a proposed mechanism for carcinogenesis in multiple types of malignancies. A history of posthitis and balanitis respectively has been reported in $45 \%$ of penile cancer patients compared to $8 \%$ of controls $(4,24)$. A meta-analysis of 443 cases found a OR of 3.82 for developing penile cancer associated with balanitis (4). Along the same lines, lichen sclerosis, a chronic inflammatory condition, as well as a progressive variant known as balanitis xerotica obliterans (BXO), have also been implicated in development of malignancy (25). Its correlation with penile cancer was originally underestimated, however, more recent literature indicates that $28-50 \%$ of penile cancer patients had a history of BXO and estimates a risk of $2-15 \%$ for developing a penile squamous cell carcinoma (26-29). The risk is mediated by the development of phimosis, a known risk factor for penile cancer (5).

\section{Obesity}

Obesity is a well-recognized risk factor for malignancies in general with a reported population attributable factor of $3.6 \%$ for all malignancies (30). The effect is more pronounced in women compared to men largely because endometrial, breast and colon cancers exhibit the strongest association with an increased BMI. Proposed mechanisms for this association include chronic inflammation and insulin resistance, as tumor progression tends to be mediated by increased inflammatory and insulin signaling pathways (31). Penile cancer specific association with obesity is quite sparse in the literature. A report by Barnes et al. in a hospital based population showed a $49 \%$ increased odds of invasive penile cancer diagnosis for every five-unit increase in BMI in overweight men (32). Their group later validated the results with a population based study showing a $53 \%$ increase in diagnosis for every five unit increase in BMI (33).

In addition to the influence of metabolic factors on cancer development and progression, obesity my lead to difficulty with genital hygiene which can result in a functional phimosis. This confers similar risks seen in patients with chronic balanitis and congenital phimosis. Obesity also presents healthcare providers with challenges in performing an adequate physical exam (32). This relationship is exemplified by a report by Abdulla et al detailing the case of a male with a neonatal circumcision who developed pT3N0 squamous cell carcinoma of the penis. Although he theoretically gained the protective effect of a neonatal circumcision, the aforementioned challenges relating to the individual's obesity with a secondarily acquired buried penis purportedly contributed to its development (34). In contrast to the above studies, a recent report of 433 penile cancer patients showed no significant association between obesity with the AJCC stage at diagnosis or disease specific survival once it has been diagnosed (35).

\section{Social factors: socioeconomic status and marital status}

Socioeconomic disparities are associated with increased cancer incidence in general (36). The literature examining these relationships with penile cancer is scarce. A population based study from Sweden reported increased risk of invasive penile cancer in those with low disposable income and low education level. Interestingly enough, the same relationship was not observed with in situ disease (37). This effect is partly due to low awareness of the disease and a delay in seeking treatment of 6 months to a year due to embarrassment about the condition $(3,38)$. With regards to marital status, a SEER database study reported that unmarried men had a 1.5 -fold increase in risk of locally advanced disease and a 1.3-fold increase in overall mortality (39). A Danish population study showed increased risks for men who were unmarried (HR 1.37), divorced (HR 1.49), or widowed (HR 1.36) when compared to married men (40). A difference was even shown when compared with men in opposite-sex cohabitation which infers the risk was likely secondary to instability of sexual relationships in single men.

\section{Premalignant lesions and immune compromise}

Premalignant lesions are benign entities that are thought to 
have the potential for malignant transformation. Some lesions are secondary to chronic inflammatory insults such as lichen sclerosis and leukoplakia. Other lesions are related to HPV infection such as giant condylomata, cutaneous horn, Bowen's disease, and erythroplasia of Queyrat (24). The immune system has a significant influence on the risk for contracting HPV as well as its infectious course and clearance, which affects the development of some premalignant lesions. HIV positive individuals as well as organ transplant recipients are known to be at an increased risk of acquiring the HPV virus (41). While most infections are cleared by the immune system, the immunocompromised individual has a reduced capacity to neutralize oncoproteins E6 and E7 and clear the HPV infection (12). As a result, patients in a chronic immunocompromised state are at a much higher risk of ano-genital HPV infection. One study found that renal transplant patients are at a 17 -fold increase in risk. On the other hand, positive HIV status was associated with a 4-fold increase in infection by multiple HPV subtypes which leads to an increased risk of developing invasive disease $(3,41)$. Considering the risks, it remains to be seen whether this at-risk population will benefit from prophylactic HPV vaccination as many of the patient have been already exposed.

\section{Smoking and marijuana}

Smoking has been implicated as a risk factor for multiple malignancy sites and penile cancer is no exception (42). Hellberg et al. showed smoking to be an independent risk factor after adjusting for confounding factors. In addition, a dose-response effect was also observed with a relative risk (RR) of 1.88 for heavy smokers when compared to light smokers and RR of 2.22 compared to non-smokers (43). A study from India of 503 cases with age matched controls showed a significant association with smoking, chewing tobacco, and the use of snuff with odds ratios ranging from 1.44 to 3.3 (44).

Although marijuana smoke exposes the patient to some of the same carcinogens as tobacco, an epidemiologic review of the association of marijuana smoke with various types of cancer found no convincing evidence of increased risk with a possible exception for testicular cancer (45). A case-control study of a population in Washington State specifically examined marijuana use and penile cancer. A weak association was observed; however, it was not statistically significant. Furthermore, the risk did not increase with more frequent use (46).

\section{UVA phototherapy}

Psoralen UV-A phototherapy (PUVA) is an effective and widely used treatment for chronic plaque psoriasis (47). While is well established that PUVA poses an increased risk of squamous cell carcinoma on non-sun-exposed skin, few studies have examined its specific association with penile cancer (48). A large prospective trial involving 892 with long term follow up revealed that patients with PUVA exposure had 95.7 times the risk of developing invasive penile cancer when compared to the general population. The risk ratio was as high as 286 times in patients exposed to high doses of PUVA (49). An update by the same author published 4 years later showed that despite genital shielding, a dose dependent association with PUVA and penile cancer persisted (50). A recent systematic review reiterated that the risk is dose dependent and can persist after cessation of treatment (47).

\section{$H P V$}

There has been a great deal of emphasis on HPV's potential for carcinogenesis in the past few years. Historically it was estimated that HPV is responsible for a large portion of cervical (96\%), anal (93\%), vaginal (64\%), oropharyngeal $(63 \%)$, and penile $(36 \%)$ cancers $(51,52)$. A recent systemic review estimates that HPV is found in $48 \%$ of penile cancer specimens. Specifically high risk serotypes 16 and 18 were found in $36.7 \%$ of the samples examined (53-56). The advent of multivalent vaccines has provided the opportunity for a novel way to mitigate the risk for development of some HPV associated malignancies. The cost-effectiveness and efficacy continues to be evaluated (54). The relationship between HPV and penile cancer as well as its implications for prevention and treatment will be discussed in detail by Dr. Giuliano in a dedicated section of this issue.

\section{Conclusions}

While penile cancer is quite rare in developed countries, it continues to be a significant public health issue in developing nations. There are wide variations across geographical and socioeconomic divides and numerous risk factors have been identified, many of which are modifiable. Public health campaigns are needed in developing countries to focus on increasing neonatal circumcision rates, combatting smoking trends, promoting better hygiene, and pursuing wide deployment of the HPV vaccine. 


\section{Acknowledgements}

None.

\section{Footnote}

Conflicts of Interest: The authors have no conflicts of interest to declare.

\section{References}

1. Pow-Sang MR, Ferreira U, Pow-Sang JM, et al. Epidemiology and natural history of penile cancer. Urology 2010;76:S2-6.

2. Mosconi AM, Roila F, Gatta G, et al. Cancer of the penis. Crit Rev Oncol Hematol 2005;53:165-77.

3. Misra S, Chaturvedi A, Misra NC. Penile carcinoma: a challenge for the developing world. Lancet Oncol 2004;5:240-7.

4. Morris BJ, Gray RH, Castellsague X, et al. The Strong Protective Effect of Circumcision against Cancer of the Penis. Adv Urol 2011;2011:812368.

5. Heller DS. Lesions and Neoplasms of the Penis: A Review. J Low Genit Tract Dis 2016;20:107-11.

6. Shavit O, Roura E, Barchana M, et al. Burden of human papillomavirus infection and related diseases in Israel. Vaccine 2013;31 Suppl 8:132-41.

7. Favorito LA, Nardi AC, Ronalsa M, et al. Epidemiologic study on penile cancer in Brazil. Int Braz J Urol 2008;34:587-91; discussion 591-3.

8. Couto TC, Arruda RM, Couto MC, et al. Epidemiological study of penile cancer in Pernambuco: experience of two reference centers. Int Braz J Urol 2014;40:738-44.

9. Koifman L, Vides AJ, Koifman N, et al. Epidemiological aspects of penile cancer in Rio de Janeiro: evaluation of 230 cases. Int Braz J Urol 2011;37:231-40; discussion 240-3.

10. Barnholtz-Sloan JS, Maldonado JL, Pow-sang J, et al. Incidence trends in primary malignant penile cancer. Urol Oncol 2007;25:361-7.

11. Hernandez BY, Barnholtz-Sloan J, German RR, et al. Burden of invasive squamous cell carcinoma of the penis in the United States, 1998-2003. Cancer 2008;113:2883-91.

12. Christodoulidou M, Sahdev V, Houssein S, et al. Epidemiology of penile cancer. Curr Probl Cancer 2015;39:126-36.

13. Arya M, Li R, Pegler K, et al. Long-term trends in incidence, survival and mortality of primary penile cancer in England. Cancer Causes Control 2013;24:2169-76.
14. Schoen EJ. Neonatal circumcision and penile cancer. Evidence that circumcision is protective is overwhelming. Bmj 1996;313:46; author reply 47.

15. Larke NL, Thomas SL, dos Santos Silva I, et al. Male circumcision and penile cancer: a systematic review and meta-analysis. Cancer Causes Control 2011;22:1097-110.

16. Wolbarst A. Circumcision and penile cancer. The Lancet 1932;219:150-3.

17. Schoen EJ. The relationship between circumcision and cancer of the penis. CA Cancer J Clin 1991;41:306-9.

18. Dillner J, von Krogh G, Horenblas S, et al. Etiology of squamous cell carcinoma of the penis. Scand J Urol Nephrol Suppl 2000:189-93.

19. Reddy DG, Baruah IK. Carcinogenic action of human smegma. Arch Pathol 1963;75:414-20.

20. Van Howe RS, Hodges FM. The carcinogenicity of smegma: debunking a myth. J Eur Acad Dermatol Venereol 2006;20:1046-54.

21. Letendre J, Saad F, Lattouf JB. Penile cancer: what's new? Curr Opin Support Palliat Care 2011;5:185-91.

22. Frisch M, Friis S, Kjaer SK, et al. Falling incidence of penis cancer in an uncircumcised population (Denmark 1943-90). Bmj 1995;311:1471.

23. Madsen BS, van den Brule AJ, Jensen HL, et al. Risk factors for squamous cell carcinoma of the penis--populationbased case-control study in Denmark. Cancer Epidemiol Biomarkers Prev 2008;17:2683-91.

24. Minhas S, Manseck A, Watya S, et al. Penile cancer-prevention and premalignant conditions. Urology 2010;76:S24-35.

25. Kantere D, Lowhagen GB, Alvengren G, et al. The clinical spectrum of lichen sclerosus in male patients - a retrospective study. Acta Derm Venereol 2014;94:542-6.

26. Pietrzak P, Hadway P, Corbishley CM, et al. Is the association between balanitis xerotica obliterans and penile carcinoma underestimated? BJU Int 2006;98:74-6.

27. Velazquez EF, Cubilla AL. Lichen sclerosus in 68 patients with squamous cell carcinoma of the penis: frequent atypias and correlation with special carcinoma variants suggests a precancerous role. Am J Surg Pathol 2003;27:1448-53.

28. Powell J, Robson A, Cranston D, et al. High incidence of lichen sclerosus in patients with squamous cell carcinoma of the penis. Br J Dermatol 2001;145:85-9.

29. Centers for Disease Control and Prevention (CDC). Cigarette smoking among adults--United States, 2006. MMWR Morb Mortal Wkly Rep 2007;56:1157-61.

30. Renehan AG, Soerjomataram I. Obesity as an Avoidable Cause of Cancer (Attributable Risks). Recent Results Cancer 
Res 2016;208:243-56.

31. Allott EH, Hursting SD. Obesity and cancer: mechanistic insights from transdisciplinary studies. Endocr Relat Cancer 2015;22:R365-86.

32. Barnes KT, Smith BJ, Lynch CF, et al. Obesity and invasive penile cancer. Eur Urol 2013;63:588-9.

33. Barnes KT, McDowell BD, Button A, et al. Obesity is associated with increased risk of invasive penile cancer. BMC Urol 2016;16:42.

34. Abdulla A, Daya D, Pinthus J, et al. Buried penis: An unrecognized risk factor in the development of invasive penile cancer. Can Urol Assoc J 2012;6:E199-202.

35. Djajadiningrat RS, van Werkhoven E, Horenblas S. Penile cancer stage, survival and body mass index. Urol Int 2015;94:220-4.

36. Clegg LX, Reichman ME, Miller BA, et al. Impact of socioeconomic status on cancer incidence and stage at diagnosis: selected findings from the surveillance, epidemiology, and end results: National Longitudinal Mortality Study. Cancer Causes Control 2009;20:417-35.

37. Torbrand C, Wigertz A, Drevin L, et al. Socioeconomic factors and penile cancer risk and mortality; a populationbased study. BJU Int2017;119:254-60.

38. Skeppner E, Andersson SO, Johansson JE, et al. Initial symptoms and delay in patients with penile carcinoma. Scand J Urol Nephrol 2012;46:319-25.

39. Thuret R, Sun M, Budaus L, et al. A population-based analysis of the effect of marital status on overall and cancerspecific mortality in patients with squamous cell carcinoma of the penis. Cancer Causes Control 2013;24:71-9.

40. Ulff-Moller CJ, Simonsen J, Frisch M. Marriage, cohabitation and incidence trends of invasive penile squamous cell carcinoma in Denmark 1978-2010. Int J Cancer 2013;133:1173-9.

41. Viens LJ, Henley SJ, Watson M, et al. Human Papillomavirus-Associated Cancers - United States, 20082012. MMWR Morb Mortal Wkly Rep 2016;65:661-6.

42. Moore TO, Moore AY, Carrasco D, et al. Human papillomavirus, smoking, and cancer. J Cutan Med Surg 2001;5:323-8.

43. Hellberg D, Valentin J, Eklund T, et al. Penile cancer: is there an epidemiological role for smoking and sexual behaviour? Br Med J (Clin Res Ed) 1987;295:1306-8.

Cite this article as: Douglawi A, Masterson TA. Updates on the epidemiology and risk factors for penile cancer. Transl Androl Urol 2017;6(5):785-790. doi: 10.21037/tau.2017.05.19
44. Harish K, Ravi R. The role of tobacco in penile carcinoma. Br J Urol 1995;75:375-7.

45. Huang YH, Zhang ZF, Tashkin DP, et al. An epidemiologic review of marijuana and cancer: an update. Cancer Epidemiol Biomarkers Prev 2015;24:15-31.

46. Maden C, Sherman KJ, Beckmann AM, et al. History of circumcision, medical conditions, and sexual activity and risk of penile cancer. J Natl Cancer Inst 1993;85:19-24.

47. Archier E, Devaux S, Castela E, et al. Carcinogenic risks of psoralen UV-A therapy and narrowband UV-B therapy in chronic plaque psoriasis: a systematic literature review. J Eur Acad Dermatol Venereol 2012;26 Suppl 3:22-31.

48. Aubin F, Puzenat E, Arveux P, et al. Genital squamous cell carcinoma in men treated by photochemotherapy. A cancer registry-based study from 1978 to 1998 . Br J Dermatol 2001;144:1204-6.

49. Stern RS. Genital tumors among men with psoriasis exposed to psoralens and ultraviolet A radiation (PUVA) and ultraviolet $\mathrm{B}$ radiation. The Photochemotherapy Follow-up Study. N Engl J Med 1990;322:1093-7.

50. Stern RS, Bagheri S, Nichols K. The persistent risk of genital tumors among men treated with psoralen plus ultraviolet A (PUVA) for psoriasis. J Am Acad Dermatol 2002;47:33-9.

51. Gillison ML, Chaturvedi AK, Lowy DR. HPV prophylactic vaccines and the potential prevention of noncervical cancers in both men and women. Cancer 2008;113:3036-46.

52. Kurdgelashvili G, Dores GM, Srour SA, et al. Incidence of potentially human papillomavirus-related neoplasms in the United States, 1978 to 2007. Cancer 2013;119:2291-9.

53. Backes DM, Kurman RJ, Pimenta JM, et al. Systematic review of human papillomavirus prevalence in invasive penile cancer. Cancer Causes Control 2009;20:449-57.

54. Stratton KL, Culkin DJ. A Contemporary Review of HPV and Penile Cancer. Oncology (Williston Park) 2016;30:245-9.

55. Spiess PE, Dhillon J, Baumgarten AS, et al. Pathophysiological basis of human papillomavirus in penile cancer: Key to prevention and delivery of more effective therapies. CA Cancer J Clin 2016.

56. Flaherty A, Kim T, Giuliano A, et al. Implications for human papillomavirus in penile cancer. Urol Oncol 2014;32:53.e1-8. 